\title{
Formação Inicial de Professores de Ciências Biológicas Mediada por Narrativas Digitais: Uma Pesquisa Baseada em Design
}

\section{Biological Sciences Pre-Service Teacher Education Mediated by Digital Storytelling: A Design Based Research}

\author{
Rosilaine de Fátima Wardenski (1) Brasil \\ Margarete Valverde Macedo ${ }^{(1)}$ Brasil \\ Maria Margarida Gomes (1) Brasil \\ Rafaela Ferreira dos Santos ${ }^{(1)}$ Brasil \\ Tais Rabetti Giannella ${ }^{(1)}$ Brasil
}

Este artigo tem como objetivo narrar o desenvolvimento, a implementação e a análise do Itinerário formativo articulador, percurso de ensino-aprendizagem situado em uma licenciatura em ciências biológicas, assim como definir princípios de design, de maneira a contribuir para construção de conhecimento e formulação de iniciativas voltadas para a formação de professores. Orientado pela pesquisa baseada em design, o estudo seguiu quatro fases: análise do problema pedagógico; desenvolvimento do artefato pedagógico; implementação e avaliação do artefato pedagógico; e reflexão para produzir princípios de design. O percurso metodológico foi desenvolvido em parceria com duas professoras da licenciatura em ciências biológicas, e as fases analisadas segundo objetivos de pesquisa específicos. Visando desestabilizar a problemática das dicotomias entre teoria e prática e entre conhecimentos pedagógicos e de conteúdo, o Itinerário formativo articulador envolveu a integração entre o componente curricular prática de ensino e uma disciplina eletiva, tendo a produção de narrativas digitais como eixo condutor. $\mathrm{O}$ objetivo da análise das narrativas digitais de oito licenciandos foi identificar marcas que indicassem caminhos para a desestabilização das dicotomias. Foram identificadas três tendências: (1) conhecimentos pedagógicos de conteúdo emergiram principalmente das narrativas articuladoras finais; (2) narrativas digitais com níveis mais elevados de reflexão mobilizaram principalmente conhecimentos pedagógicos de conteúdo; e (3) narrativas digitais com níveis mais elevados de reflexão sobre eventos motivadores o fizeram devido a maior oportunidade de problematização. $\mathrm{O}$ trabalho discute resultados do primeiro ciclo de uma pesquisa baseada em design, contribuindo com a formulação de princípios de design a refinar em ciclos posteriores.

Palavras-chave: práxis pedagógica; conhecimento pedagógico de conteúdo; narrativas digitais. 
This work aims at summarizing the development, implementation and analysis of an Articulative-Formative Itinerary, a teaching-learning method from a biology teacher education program, as well as at defining design principles to contribute to teacher education. Informed by design-based research, this study followed four phases: analysis of the educational problem; development of the pedagogical artifact; implementation and evaluation of the pedagogical artifact and; reflection to produce design principles. The methodological approach was developed in a partnership with two professors from a biology education department, and the steps were analyzed according to specific research goals. Aiming to tackle the problem of dichotomies between theory and practice and between pedagogical and content knowledge, the Articulative-Formative Itinerary (pedagogical artifact) involved the integration between teaching practice and an elective course, with the production of digital storytelling as the guiding principle for reflection. The objective of the analysis of the stories produced by eight undergraduates was to identify signs that pointed to destabilization of dichotomies. Three tendencies were identified: (1) pedagogical content knowledge emerged mainly in the final articulative stories; (2) digital stories that presented higher levels of reflection mainly mobilized pedagogical content knowledge and; (3) digital stories with higher levels of reflection on motivating events did so due to the greater opportunity for problematization. The work discusses results about the first cycle of a design-based research study, contributing to the formulation of design principles to be refined in later cycles.

Keywords: pedagogical praxis; pedagogical content knowledge; digital storytelling.

\section{Contextualizando o estudo}

Este trabalho, recorte de uma tese de doutorado, foi fundamentado pelo referencial teórico-metodológico da pesquisa baseada em design (PBD), cujo foco é o desenvolvimento e a implementação, teoricamente sustentados, de artefatos pedagógicos voltados para a solução de problemas educativos situados na prática (McKenney \& Reeves, 2013; Wang \& Hannafin, 2005). Para isso, pressupõe a imersão em contextos de ensino-aprendizagem reais e o contato direto com os sujeitos, a fim de identificar e problematizar os principais desafios que eles enfrentam em seu cotidiano. De acordo com Wang e Hannafin (2005), os pesquisadores trabalham em conjunto com os práticos (professores e estudantes) analisando o contexto, prestando atenção em suas demandas e teorias, agindo como facilitadores, adaptando-se a seus saberes e experiências, e simultaneamente propondo caminhos que possam alinhar as diferentes perspectivas na elaboração de "soluções" educativas inovadoras.

Nesse sentido, estudiosos da PBD sugerem que os relatos das pesquisas constituam-se em "narrativas de design", relatos que, de modo transparente e com base na teoria e na prática, explicitem o percurso investigativo que sustentou a elaboração do artefato pedagógico (DBRC, 2003; Wang \& Hannafin, 2005).

Assim, neste trabalho, a PBD apoiou o desenvolvimento de um artefato 
pedagógico para a formação inicial de professores de ciências biológicas. Esse processo foi teoricamente embasado e procurou responder a problemas e desafios vivenciados por formadores e licenciandos. A importância deste procedimento decorre da necessidade de aliar teoria e prática educacional, bem como de evitar iniciativas verticalizadas de formação (Nóvoa, 2007). Para isso, foi estabelecida uma parceria entre pesquisadoras da área de tecnologia educacional para o ensino de ciências e duas professoras envolvidas com um curso de licenciatura. A equipe de pesquisadoras é formada por duas alunas de doutorado (licenciadas em biologia e com mestrado em educação em ciências e saúde) e sua orientadora, com experiência na pesquisa e no desenvolvimento de atividades e materiais pedagógicos baseados em Tecnologias Digitais de Informação e Comunicação (TDIC) voltados para a educação em ciências e saúde.

Entre as professoras, uma delas pertence ao departamento de Ecologia do Instituto de Biologia (IB), é pesquisadora na área de Ecologia de insetos e possui projetos de extensão voltados para assuntos educacionais. A outra é vinculada ao departamento de didática da Faculdade de Educação da mesma universidade, pesquisadora deste campo, e responsável por acompanhar turmas durante o componente curricular prática de ensino (que inclui o estágio supervisionado obrigatório). Nesta pesquisa, foram denominadas Catarina e Clarice, respectivamente. Participaram também do estudo 19 licenciandos de uma turma de graduação, nomeados L1, L2 e assim sucessivamente, até L19.

O contexto foi um curso de licenciatura em ciências biológicas de uma universidade federal brasileira que se divide entre o ciclo básico (dois anos), voltado quase exclusivamente para a aquisição de conhecimentos específicos das ciências biológicas, e a licenciatura (dois anos), com disciplinas preferencialmente pedagógicas. Ao longo da graduação, os licenciandos devem cumprir 90 horas de disciplinas eletivas, ou seja, de uma gama de disciplinas facultativas, eles devem escolher as mais adequadas a seus interesses acadêmicos, totalizando tal carga horária. Ao final desse ciclo, os licenciandos cursam $400 \mathrm{~h}$ de prática de ensino, um componente curricular obrigatório para a conclusão do curso, embora suas características não correspondam às de uma disciplina; esse componente curricular inclui horas em sala de aula na universidade e horas nas escolas em que cumpram o estágio supervisionado obrigatório.

Em acordo com os pressupostos da PBD, tanto o desenvolvimento do artefato pedagógico quanto a pesquisa delinearam-se ao longo do estudo, à medida que o contato entre os sujeitos se aprofundava, com apoio também na literatura referente à formação de professores e ao ensino de ciências. Durante o percurso, desenvolveu-se um Itinerário formativo articulador, visando à problematização e desestabilização das dicotomias entre teoria e prática e entre conhecimentos pedagógicos e de conteúdo.

Este artigo tem como objetivo narrar o desenvolvimento, a implementação e a análise do Itinerário formativo articulador, assim como definir princípios de design, de maneira a contribuir com a construção de conhecimento sobre a formação de professores de ciências biológicas. Tendo em vista que cada uma das fases da PBD possui objetivos particulares, podendo acomodar também métodos e conceitos teóricos específicos, 
o percurso investigativo é narrado seguindo as quatro fases propostas por Reeves (2000): análise do problema pedagógico; desenvolvimento do artefato pedagógico; implementação e avaliação do artefato pedagógico; e documentação e reflexão para produzir princípios de design.

Foram respeitadas todas as normas éticas destinadas à pesquisa envolvendo seres humanos e formuladas pela Comissão Nacional de Ética em Pesquisa (Conep-MS), e o estudo recebeu aprovação do Conselho de Ética do Instituto de Estudos em Saúde Coletiva (IESC/UFRJ) sob o número: 2.772.224.

\section{Referencial teórico-metodológico: a pesquisa baseada em design}

A Pesquisa baseada em design (PBD) é um referencial teórico-metodológico intervencionista, pois tem como pressuposto o desenvolvimento de artefatos pedagógicos que devem ser implementados nos contextos reais, a fim de lidar com os desafios presentes no cotidiano. A PBD tem como um de seus princípios-chave a relação entre a teoria e a prática, uma vez que almeja desenvolver compreensão teórica capaz de ser útil para a prática e, ao mesmo tempo, implementar e analisar intervenções que sirvam como objeto de pesquisa para a construção de conhecimentos teóricos (McKenney \& Reeves, 2013).

A opção pelo termo artefato neste trabalho se deu no sentido de demarcar o que muitos estudiosos do campo da tecnologia educacional criticam em relação à usual visão de produto como algo estanque e criado à parte dos processos e atores do contexto de ensino-aprendizagem (Amiel \& Reeves, 2008). Temos utilizado a denominação artefato pedagógico buscando reforçar o caráter vivo, situado e iterativo das "soluções" desenvolvidas a partir da PBD em contextos educativos (Juuti \& Lavonen, 2006).

Assim foi distribuído o conteúdo metodológico pelas fases propostas por Reeves (2000) para o percurso da PBD.

$\mathrm{Na}$ análise do problema pedagógico, que envolve a pesquisa, identificação e análise do problema que orientará o desenvolvimento do artefato, com base na interação entre os sujeitos parceiros, como também no aprofundamento teórico por parte dos pesquisadores, foram realizadas duas entrevistas individuais, um encontro coletivo com as professoras parceiras e nove entrevistas coletivas com os 19 licenciandos divididos em grupos.

No desenvolvimento do artefato pedagógico, realizado com base na teoria norteadora e em negociação constante entre sujeitos e parceiros, levando em conta as especificidades do contexto em que a pesquisa se desenvolve, foi delineado o Itinerário formativo articulador, um percurso de ensino-aprendizagem integrado por duas disciplinas e constituído por estratégias e materiais educativos voltados para a articulação entre teoria e prática, bem como entre conhecimentos pedagógicos e de conteúdo. Ao longo de 17 reuniões entre as pesquisadoras e as professoras, as pesquisadoras mediaram o percurso, sintetizando, sistematizando e propondo caminhos comuns às expectativas das professoras. 
Na implementação e avaliação do artefato pedagógico, em que ocorre a intervenção propriamente dita no contexto educacional e busca-se compreender e avaliar como e o quanto o artefato pedagógico desenvolvido contribuiu para a solução do problema pedagógico, a análise concentrou-se nos dados produzidos por oito licenciandos que participaram da intervenção (narrativas digitais construídas por eles durante o percurso).

$\mathrm{Na}$ documentação e reflexão para produzir princípios de design, envolvendo revisitar todas as fases do processo e permitindo sua revisão e o desenvolvimento dos princípios, buscou-se construir conhecimentos sobre a formação inicial de professores de ciências biológicas, mais especificamente.

Essas fases não ocorrem de maneira linear, mas demarcam características comuns e especificidades do curso da pesquisa, auxiliando a compreensão desse processo (Reeves, 2000).

Os dados obtidos em todas as fases foram examinados de acordo com a análise temática de conteúdo de Bardin (2004), que consiste em descobrir os núcleos de sentido que compõem uma comunicação. Operacionalmente, foram observadas as etapas básicas: pré-análise, fase de organização e escolha dos dados; exploração, em que se buscou uma leitura mais aprofundada dos dados, procurando estabelecer relações entre as falas dos sujeitos e as categorias de análise; e interpretação dos dados, que correspondeu à correlação entre os dados obtidos, o quadro teórico da pesquisa e os objetivos propostos (Bardin, 2004).

A seguir, é relatado o caminho percorrido em cada uma das fases da PBD, procurando valorizar os aspectos contextuais e descrevendo os principais resultados encontrados.

\section{Definição e análise do problema pedagógico}

A fim de definir e caracterizar o problema pedagógico que orientou o desenvolvimento do artefato pedagógico, foram analisadas nessa fase as percepções de licenciandos e professoras a respeito da profissão docente e do ensino de ciências e biologia.

O que motivou o início desse projeto foi uma inquietação compartilhada pela professora Catarina, que buscou uma parceria para pensar materiais educativos sobre a temática "insetos" a fim de apoiar a prática docente na educação básica. Naquele momento, começou-se a discutir os desafios da docência e, indo além daquela preocupação inicial sobre os recursos didáticos em si, passou-se a pensar como problemática a complexidade do ensino de ciências e, por consequência, da formação inicial de professores dessa área. Estabeleceu-se, então, a segunda parceria, com Clarice. Nascia ali um percurso de problematização sobre o papel docente e as abordagens de ensino de ciências no qual os olhares das professoras se cruzavam em busca da construção de um projeto comum. $\mathrm{Na}$ análise do problema pedagógico, foi considerado também o olhar dos licenciandos, pois suas percepções se encontram diretamente relacionadas com os desafios da formação docente. Foram, portanto, realizadas entrevistas com as professoras e com os 
19 licenciandos, visando compreender tais desafios.

Os sujeitos da pesquisa em pauta manifestavam percepções sobre a formação construídas a partir de diferentes pontos de vista, com variados graus de elaboração. Os licenciandos expressavam percepções com base, principalmente, em suas experiências como estudantes, incluindo as observações das práticas de antigos professores. As professoras, por sua vez, fundamentavam suas considerações a partir de suas vivências docentes e trajetórias de pesquisa, manifestando projeções e conjecturas sobre seu processo de formação. Suas falas auxiliaram a construção de entendimento das percepções manifestadas pelos licenciandos, servindo como base para a análise e identificação do problema pedagógico.

No que diz respeito às percepções dos licenciandos sobre o papel docente, um ponto recorrente apontado por 12 participantes foi o foco nas habilidades de transmissão de conhecimentos: “Tem que saber essa didática, saber se comportar lá na frente, saber e ter essa interação com os alunos de uma forma a mostrar o conteúdo de biologia pra eles" (L8). Nessa direção, os licenciandos buscaram refletir sobre como melhorar o processo de transmissão de conhecimentos e apontaram aspectos tais como interesse quanto ao aprendizado dos estudantes, dedicação e capacidade de controlar a turma. $\mathrm{Ou}$ seja, destacaram habilidades genéricas que, segundo Cardoso et al. (2012), representam visões do senso comum que levam a prática do professor a um status profissional limitado e simplificam sua complexidade.

A maior parte desses sujeitos $(n=11)$, quando indagada sobre o aprendizado da profissão docente, demonstrou ter uma percepção de que professores são bons ou não por natureza, ou só aprendem a ser professores a partir da prática. Há, portanto, ênfase no dom, que desconsidera a necessidade de esforço, trabalho e reflexão na ação cotidiana do professor e, segundo Carvalho e Gil-Perez (2011), leva a prática docente a ser considerada atividade menos importante em relação a outras profissões. Consequentemente, quando indagados se é possível aprender a ser professor, esses 11 licenciandos deram mais destaque à prática, como se a atividade docente fosse desprovida de teorização.

Outros oitolicenciandos, por suavez, ressaltaramaimportância dos conhecimentos teóricos para a ação docente, apontando que as disciplinas de formação pedagógica constituem oportunidade de reflexão acerca de diferentes teorias do campo educacional, auxiliando na formação da pessoa e, consequentemente, do professor. "A licenciatura te ajuda na tua preparação enquanto profissional [...] E tem vários pensamentos que a gente muda ao longo do tempo" (L6). Em geral, a percepção de tais sujeitos sobre o trabalho docente distanciava-se daquela de transmissores de informações, destacando a necessidade de auxiliar os alunos a buscar e construir novos conhecimentos. Pareceu emergir, assim, uma relação entre as percepções da importância de teorias pedagógicas e o papel do professor no processo de ensino-aprendizagem. Dessa forma, foi possível inferir que conhecimentos teóricos desenvolvidos ao longo da formação podem auxiliar os licenciandos a problematizar sua profissão. Segundo Silva (2011), a teoria incorpora um conjunto de concepções e valores que atua como base para um determinado modo 
de pensar, permitindo aos indivíduos interpretar os eventos e situações com que se deparam ao longo da profissão e buscar formas adequadas de agir.

As professoras também apontaram que os licenciandos, muitas vezes, colocam a transmissão de conteúdos em uma posição central, além de se interessar fundamentalmente pela prática pedagógica, sem considerar os conhecimentos teóricos. A esse respeito, Clarice, mencionou a relevância da relação entre teoria e prática, destacando que o licenciando precisa compreender a importância dos conhecimentos teóricos e aprender a desenvolvê-los a fim de facilitar a promoção de mudanças na prática pedagógica.

Eu acho que os alunos têm que aprender a colocar em diário a teoria e a prática, sem desfavorecer nenhuma delas. Porque o aluno, muitas vezes quando chega nas minhas disciplinas, acha que ir pra escola, dar aula e fazer materiais didáticos já é suficiente para se tornar professor. Eu acho que isso é muito importante, mas não é suficiente. Eu acho que tem toda uma história de conhecimento teórico acumulada, tanto no campo da biologia quanto no campo dos conhecimentos pedagógicos, que é muito importante para o professor (Clarice, entrevista inicial).

De acordo com Silva (2011), a não compreensão da relação entre teoria e prática pode ser um problema, pois, para que as práticas pedagógicas possam ser transformadas, é necessário que sejam refletidas e problematizadas. Dessa forma, a não percepção por parte dos docentes ou futuros docentes quanto às visões que permeiam as ações pedagógicas pode conduzir à dicotomização entre teoria e prática.

Com relação ao ensino de ciências nas escolas e suas abordagens pedagógicas, oito licenciandos defenderam a necessidade de mudanças, sem, contudo, saber caracterizar sua natureza. Em suas falas, ilustravam essas mudanças por atividades dinâmicas ou práticas, porém, ao defendê-las, descreviam atividades mecânicas e transmissivas, sem considerar a possibilidade de preparar os alunos para um processo de construção de conhecimentos. Esses sujeitos, de maneira geral percebiam a ciência como um processo objetivo, descrevendo-o a partir do método científico clássico.

Por outro lado, 11 licenciandos sugeriram abordagens que coloquem os alunos em contato com o processo de construção de conhecimento científico, a partir de uma perspectiva mais investigativa ou da contextualização dos conteúdos estudados por meio da articulação com problemas sociais e ambientais: "Então é aquilo que a professora falou, que muito importante para o ensino de ciências é o ensino investigativo, porque ele meio que te estimula a realmente aprender a fazer ciência e não ficar só naquele teórico, só decorando nomes" (L4).

De maneira geral, essas propostas apareceram naqueles grupos cujos licenciandos haviam discutido e refletido, durante as próprias entrevistas, mais profundamente sobre a ciência, o processo de construção do conhecimento científico e as relações entre seu desenvolvimento e as problemáticas ambientais e sociais. Abordando a educação em ciências, Batista e Silva (2018) afirmam que os sujeitos têm percepções relacionadas entre si quanto ao ensino e à natureza das disciplinas de referência. 
Muitas questões apontadas pelos licenciandos ao discutir o ensino de ciências nas escolas convergiam para as problemáticas levantadas pelas professoras. Um exemplo disso foi a constatação de que os conteúdos científicos devem ser apresentados de maneira contextualizada, aspecto amplamente argumentado por Catarina. "Então ele ver um esgoto a céu aberto ali e ele ser capaz de associar aquilo com a disciplina, com os conteúdos que ele viu, com as doenças, com os problemas sociais". A professora defendeu um ensino para além do conteúdo stricto sensu, demonstrando a intenção de que os futuros professores tenham ampla visão das diferentes competências e habilidades que podem ser trabalhadas em sala de aula. Em sua opinião, entretanto, embora percebam a necessidade de fazer essas articulações, muitos professores têm dificuldade para colocar seus reais objetivos em prática.

Clarice e Catarina relacionaram essa dificuldade, em certa medida, à estrutura curricular do curso de licenciatura em Ciências Biológicas, que, de acordo com Clarice, gera dificuldade para o licenciando realizar articulações entre os conteúdos apreendidos e as diferentes abordagens para seu ensino. Essa problemática também é apontada na literatura, e Carvalho e Gil-Pérez (2011) afirmam que tal estruturação estimula a dicotomização entre conhecimentos pedagógicos e de conteúdo.

Diante dessas discussões, o problema pedagógico analisado sob a perspectiva do presente estudo pode ser sintetizado pela existência de duas dicotomias que permeiam a formação inicial de professores: entre teoria e prática, e entre conhecimentos pedagógicos e de conteúdo.

\section{Desenvolvimento do artefato pedagógico}

Caracterizado o problema, essa fase teve como objetivo a definição do referencial norteador e das estratégias formativas adotadas no desenho do artefato pedagógico. Assim, esta seção apresenta o quadro teórico e sua contribuição para o desenho do Itinerário formativo articulador, bem como as estratégias formativas adotadas, relacionando-as com os problemas pedagógicos anteriormente definidos. Nessa etapa houve 17 reuniões de trabalho, e todo o percurso de definição das estratégias foi pautado no debate e na negociação com as parceiras.

\section{O quadro teórico norteador}

Dois referenciais centrais nortearam o desenvolvimento do Itinerário formativo articulador: i) a perspectiva da práxis pedagógica, que pode fortalecer o processo reflexivo como algo intrínseco à prática, colocando-se como caminho para a desestabilização da dicotomia entre teoria e prática na ação docente (Freire, 1987; Silva, 2011); e ii) o conhecimento pedagógico de conteúdo, que, ao auxiliar a compreensão do modo como esses aspectos se relacionam na prática docente, aponta caminhos para ajudar os licenciandos a tomar consciência da relação entre esses conhecimentos (Newsome, 2002; Shulman, 1987; 2014).

A práxis pedagógica, vista como uma forma de relação da teoria com a prática, é 
uma noção mediada pelo trabalho e dele originada (Silva, 2011; Tardif, 2002). Pensando na profissão docente, Tardif (2002) toma como base o conceito de trabalho de Marx, ou seja, uma prática que provoca transformações reais não só no objeto ou situação de trabalho, mas também no trabalhador. A partir disso, Tardif (2002) afirma que a identidade do professor é modificada durante a práxis, tendo em vista que ideias, funções e interesses da profissão vão se tornando parte de sua identidade. Tal noção estaria diretamente relacionada com epistemologias do trabalho do professor que age em função de certas concepções sobre sua própria ação e sobre as finalidades e consequências dessas ações (Tardif, 2002). Assim, a práxis pedagógica teria a perspectiva de uma ação que cria novos sentidos, envolve o conhecimento do objeto, o estabelecimento de finalidades e, posteriormente, a intervenção com o objetivo de gerar transformação.

Aprofundando essa ideia, Zeichner (2008) destaca que, além da reflexão acerca da experiência, é necessário estimular uma compreensão das instituições e estruturas em que o trabalho docente se desenvolve, a fim de favorecer a busca de práticas educativas mais justas e democráticas. Para isso, os autores defendem a elevação da prática à condição de práxis, que significa a prática pensada e refletida (Freire, 1987). De acordo com Freire (1987), a mera atividade teórica não leva à transformação da realidade, não se objetiva e não se materializa, como também a prática por si mesma não é capaz de modificar-se. Caberia, portanto, aos sujeitos elevar a consciência sobre seu mundo, saindo de uma concepção ingênua.

Para alcançar a práxis pedagógica, os autores defendem uma reflexão fundamentada também por referenciais teóricos críticos (Freire, 1987; Zeichner, 2008). De acordo com Silva (2011), as teorias podem se referir tanto às ideias que os professores elaboram ao longo do tempo quanto àquelas construídas a partir das produções e reflexões resultantes dos estudos em ciências sociais, como sociologia e psicologia. Apesar de diferirem entre si, essas visões teóricas se relacionam e constituem um modo de pensamento que permite a interpretação dos eventos e das situações com que o professor se depara, estimulando determinadas formas de agir.

A práxis pedagógica, portanto, como uma prática teórica e reflexivamente embasada com vistas à transformação pedagógica, pode auxiliar não só o questionamento de assuntos relacionados à docência, mas também a construção de conhecimentos que colaboram na profissionalização do professor (Santos et al., 2018). Nessa direção, Shulman (1987), ao propor o constructo do conhecimento pedagógico de conteúdo (pedagogical content knowledge - PCK), destaca o papel da reflexividade docente para sua formação. Segundo o autor, uma prática educativa reflexiva possibilita a construção de novos conhecimentos, tanto sobre conteúdos que devem ser abordados no ensino quanto sobre alunos e aspectos pedagógicos em si. $\mathrm{O}$ autor tem como base para seu trabalho críticas a pesquisas que traçam generalizações sobre as ações dos professores, desconsiderando contextos e conteúdos de ensino. Ao pensar as especificidades das áreas de atuação e defender que os professores possuem teorias implícitas ou explícitas sobre suas disciplinas e sobre o modo como devem ser ensinadas, Shulman (1987) busca 
resgatar o conhecimento de conteúdo, denominando-o "paradigma perdido". Assim, o PCK representa a integração de saberes e habilidades em um mesmo conhecimento, ajudando o professor a pensar como tópicos, problemas ou questões específicas de determinada área são organizados, representados e adaptados aos interesses e habilidades dos alunos.

Os conhecimentos pedagógicos são, segundo Shulman (1987), a união de uma diversidade de conhecimentos que se relacionam entre si, incluindo conhecimentos sobre princípios e estratégias utilizados na gestão e organização da turma; sobre currículo e políticas educacionais; sobre os alunos e suas características; e sobre contextos educacionais. Tais conhecimentos podem resultar, muitas vezes, da interação de conhecimento pedagógico geral, derivado das pesquisas na área de educação, e conhecimento pedagógico pessoal, composto pelas crenças e experiências pessoais (Oliveira, 2017). O processo de reflexão promove, de acordo com Shulman (1987), a interação entre conhecimentos pedagógico geral e pessoal, fazendo com que novas percepções sejam formadas. Com isso, é possível observar que os conhecimentos pedagógicos podem ser construídos com base na problematização das percepções trazidas pelos sujeitos.

Quanto aos conhecimentos de conteúdo, a definição inicial proposta por Shulman (1987) é: conhecimentos específicos de cada área de ensino, incluindo conceitos, teorias e procedimentos, ou seja, o que vai ser ensinado aos alunos. Complementando o trabalho de Shulman, Newsome (2002) destaca que esses conhecimentos são diferentes e específicos, de acordo com a natureza da disciplina em questão. Assim, no âmbito do ensino de ciencias, o conhecimento de conteúdo contemplaria as visões relacionadas com o conhecimento científico e sua construção. Gabriel (2016) menciona o surgimento do discurso da ciência como produtora de uma verdade científica durante a modernidade, como expressão de uma razão libertadora, que poderia conduzir à formação de sujeitos emancipados intelectualmente. Naquele contexto, o conteúdo escolar carregava, historicamente, discursos relacionados à ciência, razão, objetividade, verdade.

Os questionamentos em relação a uma visão engessada de ciência e tecnologia (CT) teriam contribuído para a quebra do modelo linear de progresso, dando origem a um movimento denominado Ciência-Tecnologia-Sociedade (CTS), que tem como objeto de estudo e discussão os aspectos sociais da ciência e da tecnologia, ou seja, suas consequências sociais (Bazzo et al., 2003). Segundo Rosa (2014), junto com sua transposição para o campo educacional (que influenciou a difusão de programas e materiais educativos), esse movimento ganhou alusão ao meio ambiente, incluindo a letra "A" na sigla, que passou a ser CTSA (Ciência, Tecnologia, Sociedade e Ambiente).

Considerando que a incorporação das discussões CTSA na formação de professores pode estimular uma ressignificação da ideia de conteúdo escolar, o papel da práxis pedagógica para potencializar esse processo torna-se fundamental. Segundo Freire (1987), o diálogo problematizador inerente à práxis é importante para a elaboração de novos conhecimentos e de novos significados acerca da realidade. Na perspectiva da 
educação libertadora proposta pelo autor, o conteúdo é um instrumento de compreensão dos problemas cotidianos, visando a um processo de conscientização e libertação de educandos e educadores.

A dicotomização entre teoria e prática e entre conhecimentos pedagógicos e de conteúdo vem sendo historicamente abordada como um desafio para a formação de professores (Madeira, 2012). Assim, o estágio supervisionado obrigatório constitui contexto oportuno para a investigação. Em situações semelhantes, a fim de contribuir com a reflexão, frequentemente os licenciandos são estimulados a desenvolver relatórios ou memoriais, produções escritas autorais, materializando em um texto as vivências e reflexões decorrentes de suas inserções nas escolas (Nunes \& Ventorim, 2017). Esse tipo de produção se encaixa no gênero narrativo, de acordo com a definição de Larrosa (2004).

$\mathrm{Na}$ formação de professores, a autoria, bem como o registro das ações planejadas e implementadas, é apontada como de extrema importância, dado que a prática de escrever sobre o que se faz e o que se deseja fazer está atrelada a certo afastamento espacial e temporal. De acordo com autores como Nóvoa (2007) e Zeichner (2008), a formação dos professores depende mais dessa reflexividade crítica a respeito das próprias práticas do que da acumulação de conhecimentos ou técnicas.

Em decorrência e considerando a capacidade das tecnologias digitais de informação e comunicação (TDIC) para potencializar as vantagens da tradicional "contação de histórias", como apontado por Almeida e Valente (2012), torna-se relevante a possibilidade de construção de narrativas digitais (ND) pelos licenciandos, a fim de estimular a reflexão. Esses recursos podem facilitar a narratividade devido à articulação entre diferentes linguagens, como textos, sons e imagens estáticas ou em movimento (Almeida \& Valente, 2012). Além disso, o trabalho de pesquisar, selecionar, criar materiais, analisar, organizar e combinar diferentes linguagens incentiva a reflexão e o aprendizado (Rodrigues, 2017).

Acreditamos que a produção de ND no contexto da cultura digital pode criar caminhos e facilitar o desenvolvimento da autoria que, segundo Ribeiro, Carvalho e Santos (2018), ocorre quando os sujeitos vão além da condição de consumidores de conteúdos, passando também a criar, disponibilizar e compartilhar materiais e escritas por eles elaborados.

Assim, o desenvolvimento do artefato pedagógico neste estudo teve como base as perspectivas da práxis pedagógica e do PCK. Além disso, a produção de ND destacouse como forma de contribuir para o caminho de problematização e desestabilização das dicotomias identificadas na fase de definição e análise do problema pedagógico.

\section{As estratégias de formação e o Itinerário formativo articulador}

Ao longo dessa fase, foi feita a opção pelo desenvolvimento de um Itinerário formativo articulador, integrando o componente curricular prática de ensino, coordenado por Clarice, e uma disciplina eletiva ministrada por Catarina, a fim de articular diferentes 
saberes e contextos de formação. Durante 17 reuniões, foram detalhadas demandas relacionadas a cada uma das dicotomias (entre teoria e prática e entre conhecimentos pedagógicos e de conteúdo), e delineadas estratégias formativas com vistas a atender a essas demandas.

No que diz respeito à primeira dicotomia, foram escolhidas três estratégias: a) observação a partir do estranhamento do ambiente escolar e do trabalho do professor, visando à construção de conhecimentos a partir da problematização do que é vivenciado; b) planejamento didático coletivo e embasado teoricamente, a fim de evitar planejamentos burocráticos; e c) implementação das atividades planejadas no contexto escolar, a fim de estimular um estágio supervisionado obrigatório participativo.

Com relação à dicotomia entre conhecimentos pedagógicos e de conteúdo, duas estratégias foram definidas: a) investigação de temáticas CTSA como foco das atividades a planejar e implementar pelos licenciandos, a fim de lhes ampliar a visão acerca do conteúdo escolar; b) foco nas demandas dos professores regentes como base para a escolha das temáticas CTSA a abordar, visando ao desenvolvimento de planejamentos integrados ao cotidiano escolar.

No formato final do Itinerário formativo articulador, o componente curricular prática de ensino foi dividido em dois contextos: a) estágio supervisionado obrigatório, em que os licenciandos acompanharam os professores regentes em suas turmas, observando as aulas e planejando e implementando atividades, tendo sido parte dessas atividades desenvolvida em conjunto com a disciplina eletiva; e b) sala de aula, com a professora Clarice, envolvendo discussões sobre a dinâmica de realização dos estágios de maneira geral e a inserção dos licenciandos na escola, além de dinâmicas de planejamento e implementação de atividades pedagógicas.

$\mathrm{Na}$ disciplina eletiva, por sua vez, os licenciandos foram estimulados a problematizar suas visões acerca do conteúdo escolar, com base na perspectiva da investigação de temáticas CTSA, o que aconteceu em três momentos: i) temáticas controversas em debate que abarcou discussões sobre problemáticas CTSA e maneiras possíveis de as trabalhar nas escolas; ii) planejamento educativo: temas socialmente relevantes em foco, em que os licenciandos escolheram uma problemática (podendo ser ou não uma das discutidas no momento anterior) e construíram uma atividade pedagógica. Esses dois primeiros momentos foram trabalhados a partir de temáticas relacionadas com insetos, como forma de aproveitar o potencial desses animais para lidar com problemáticas sociais e ambientais amplas; e iii) implementação de atividades investigativas situadas na demanda escolar, tendo como base conceitos científicos demandados pelos professores regentes e implementadas no contexto escolar. Houve, portanto, articulação com o componente curricular prática de ensino, e a atividade desenvolvida foi organizada de acordo com a distribuição dos licenciandos em seus estágios e os currículos de cada ano escolar.

O desenvolvimento de narrativas digitais (ND) foi sugerido para ser o eixo mediador central do Itinerário formativo articulador em função de sua capacidade 
de articular contextos, conhecimentos e estratégias de formação. Para sua produção e compartilhamento, foi utilizada a rede social Facebook, ferramenta escolhida pelos próprios licenciandos.

No âmbito do componente curricular prática de ensino, foi solicitada a produção de uma narrativa por mês, em formato livre. As ND referentes aos meses de abril e maio foram individuais e poderiam versar tanto sobre eventos presenciados pelos licenciandos nas escolas quanto sobre atividades realizadas por eles durante os estágios. Já na disciplina eletiva, as ND tiveram relação com os momentos descritos, tendo sido parte produzida individualmente e parte em grupo. Aquelas relativas aos dois primeiros momentos tinham como base uma reflexão sobre a visão ampliada sobre conteúdo escolar, o que foi estimulado a partir de temáticas CTSA.

Além disso, foram produzidas também narrativas articuladoras finais, motivadas por atividade desenvolvida na disciplina eletiva (simultaneamente em contato com professores regentes) e implementadas nas escolas em que eles realizaram o estágio supervisionado obrigatório. Essas ND diziam respeito tanto ao mês de junho do componente curricular prática de ensino quanto ao último momento da disciplina eletiva.

\section{Implementação e avaliação do artefato pedagógico}

Nessa fase, que diz respeito à intervenção propriamente dita, as professoras, as pesquisadoras e oito licenciandos (que cursaram a disciplina eletiva juntamente com o componente curricular prática de ensino) vivenciaram a implementação do Itinerário formativo articulador desenvolvido. Nesse processo, realizado ao longo do primeiro semestre de 2018, os licenciandos produziram ND que estimularam a reflexão, a construção e a integração de conhecimentos, além de servir como material de análise. O objetivo da análise, portanto, foi identificar marcas que indicassem caminhos para a desestabilização das dicotomias entre teoria e prática e entre conhecimentos pedagógicos e de conteúdo, considerando as estratégias formativas do Itinerário formativo articulador.

Neste artigo, a análise concentrou-se nas narrativas digitais baseadas no relato sobre a convivência direta nas escolas com professores regentes e alunos, pois essas ND tiveram o formato de "contação de histórias", como definido por Almeida e Valente (2012). Assim, foram selecionadas as ND referentes a abril e maio do componente curricular prática de ensino (oito ND individuais em cada mês), como também as narrativas articuladoras finais (quatro ND). Com relação a estas últimas, a quantidade menor de narrativas decorreu do fato de os licenciandos se organizarem de acordo com as escolas e turmas que estavam acompanhando. Assim, uma foi realizada em grupo, uma em dupla, e duas individualmente. Foram analisadas, portanto, 20 narrativas digitais.

O foco dessa análise elegeu discutir os fenômenos da práxis pedagógica e da construção do conhecimento pedagógico de conteúdo (PCK). Com relação à práxis pedagógica, nos baseamos na definição dada por Freire (1987) de uma prática reflexiva, visando a uma ação capaz de criar novos sentidos. Concretamente, nos apoiamos na 
abordagem de Moon (2011) para caracterizar níveis de reflexão. A autora aponta diversos aspectos que, se encontrados em conjunto em uma representação (como relatos orais e escritos) podem nos ajudar a compreender os níveis de reflexão que os indivíduos conseguiram atingir. Nessa abordagem, a base das representações é uma descrição de algum evento que, se encontrado sozinho, caracteriza uma escrita descritiva. O nível seguinte é o de reflexão descritiva, que ocorre quando o sujeito aponta, junto com a descrição do evento, as questões para reflexão, ou realiza uma volta para o evento, havendo um diálogo interno. No nível de reflexão crítica, a autora destaca apontamentos sobre mudanças nas próprias visões dos autores a partir do evento. No que diz respeito à reflexão dialógica, destaca-se a evidência de autoquestionamento e o reconhecimento de que o evento ocorreu em um contexto específico. Analisar esses níveis de reflexão foi a forma adotada, neste trabalho, para caracterizar possíveis elos entre teoria e prática.

Além disso, na análise das ND, procuramos identificar marcas de mobilização de conhecimentos pedagógicos, de conteúdo e PCK, utilizando categorias com base em dimensões do conhecimento apontadas por diferentes autores (Ball et al. 2008; Carvalho \& Gil-Perez, 2011; Shulman, 1987; 2014). Essas categorias foram ressignificadas para serem aplicadas em nossa pesquisa, pois os trabalhos de origem apoiavam-se, especialmente, em dados coletados por meio de observações de aula, enquanto nossos dados estavam centrados nas narrativas digitais de licenciandos. Essas ND foram desenvolvidas em um contexto de formação inicial, abordando questões que os sujeitos não estavam acostumados a ver e problematizações sobre assuntos e eventos nunca vivenciados ou problematizados a partir de um lugar docente. Assim, os aspectos apontados por eles geralmente não diziam respeito a conhecimentos consolidados, consistindo antes em considerações e reflexões, potencialmente precursoras de conhecimentos da atividade docente.

Os conhecimentos pedagógicos identificados nas ND foram: a) conhecimento pedagógico geral, categoria que engloba reflexões desenvolvidas sobre estratégias que, segundo os licenciandos, eram ou poderiam ser utilizadas pelos professores a fim de apoiar e/ou melhorar o processo de ensino-aprendizagem; b) conhecimento sobre os alunos, encontrados em narrativas digitais que tiveram como ponto de partida observações e reflexões sobre os comportamentos, reações e atitudes dos alunos; e c) conhecimentos sobre os contextos escolares, envolvendo os diversos conhecimentos que circulam na escola, desde o espaço de sala de aula, incluindo questões de gestão e administração, assim como aspectos gerais da cultura e comunidade escolar.

Acreditamos que, ao observar aulas, planejar atividades einteragir com professores e alunos, os licenciandos refletiam e mobilizavam conhecimentos pedagógicos de conteúdo mais frequentemente do que pode ser percebido pela análise das ND, tendo em vista que esse processo é intrínseco à prática de todo professor (Ball et al., 2008). Neste trabalho, definimos o PCK tendo como base a ideia de que é necessário estimular a desnaturalização dos conteúdos com os quais os licenciandos estão familiarizados, mas para isso, eles precisam ao menos notar o que está sendo posto como conteúdo. 
Assim, optamos por classificar entre os conhecimentos pedagógicos de conteúdo apenas as reflexões que traziam, de maneira explícita, aspectos relacionados com as ciências biológicas, especificamente.

Os conhecimentos de conteúdo diziam respeito ao conhecimento de contéudo conceitual; sobre orientações metodológicas utilizadas nas ciências; e sobre orientações CTSA. Estes últimos são apontados por Carvalho e Gil-Perez (2011) para a realização de atividades investigativas e foram importantes nessa pesquisa devido ao objetivo de estimular a ampliação da ideia de conteúdo escolar por parte dos licenciandos. Os conhecimentos de conteúdo foram amplamente identificados nas narrativas digitais desenvolvidas exclusivamente para o contexto da disciplina eletiva e, portanto, não aparecem nas ND encontradas neste artigo.

As dimensões de conhecimentos pedagógicos de conteúdo, por sua vez, foram: a) conhecimentos sobre os conhecimentos dos alunos, que incluem uma compreensão do conhecimento adquirido pelos estudantes sobre conteúdos escolares específicos, suas dificuldades e estilos de aprendizagem para aprender esses conteúdos; e b) conhecimentos sobre estratégias de ensino-aprendizagem e sua utilização para diferentes contextos e objetivos, definido como qualquer estratégia de ensino que permite adequar os conteúdos a abordar em sala de aula, facilitando a compreensão dos alunos, de acordo com a natureza desses conteúdos.

Analisando as ND de acordo com os níveis de reflexão e tipos de conhecimento, e tendo como objetivo central identificar marcas que indicassem caminhos para a desestabilização das dicotomias entre a teoria e a prática e entre conhecimentos pedagógicos e de conteúdo, foi possível caracterizar três tendências principais. As tendências foram identificadas a partir da análise temática de conteúdo de todo o conjunto de ND $(n=20)$. Na apresentação desses resultados, foram elencadas aquelas ND e, em especial, aqueles excertos que melhor pudessem representar cada tendência.

A primeira tendência indica que os conhecimentos pedagógicos de conteúdo emergiram principalmente nas narrativas articuladoras finais, pois tiveram como base conhecimentos sobre estratégias de ensino-aprendizagem e sua utilização para objetivos educativos específicos. Destaca-se que as ND do componente curricular prática de ensino mobilizaram sobretudo conhecimentos pedagógicos, e aquelas referentes à disciplina eletiva apresentaram reflexões relacionadas a conhecimentos de contéudo. A Figura 1 estabelece uma comparação entre as ND do componente curricular prática de ensino e as narrativas articuladoras finais, com relação à mobilização de conhecimentos. Como se pode observar, o total de narrativas articuladoras finais teve como base o PCK. 


\begin{tabular}{|c|c|c|}
\hline & $\begin{array}{l}\text { Narrativas do componente } \\
\text { curricular prática de ensino (n } \\
=16 \text { ) }\end{array}$ & Narrativas articuladoras finais $(n=4)$ \\
\hline $\begin{array}{l}\text { Conhecimentos } \\
\text { pedagógicos }\end{array}$ & $\begin{array}{l}\text { Conhecimento pedagógico geral } \\
(\mathrm{n}=3) \\
\text { Conhecimentos sobre os alunos } \\
(\mathrm{n}=3) \\
\text { Conhecimentos sobre os } \\
\text { contextos educacionais }(\mathrm{n}=6)\end{array}$ & $\mathrm{n}=0$ \\
\hline $\begin{array}{l}\text { Conhecimentos } \\
\text { pedagógicos de } \\
\text { conteúdo }\end{array}$ & $\begin{array}{l}\text { Conhecimentos sobre os } \\
\text { conhecimentos dos alunos } \\
(\mathrm{n}=2) \\
\text { Conhecimentos sobre estratégias } \\
\text { de ensino-aprendizagem }(\mathrm{n}=2)\end{array}$ & $\begin{array}{l}\text { Conhecimentos sobre estratégias de } \\
\text { ensino-aprendizagem }(\mathrm{n}=4)\end{array}$ \\
\hline
\end{tabular}

Figura 1. Tipos de conhecimentos mobilizados nas narrativas do componente curricular prática de ensino e nas narrativas articuladoras finais

Para ilustrar essa tendência, são apresentadas a narrativa de L11 referente ao mês de abril, quando os alunos vivenciavam a estratégia de estranhamento do contexto escolar, e a narrativa articuladora final de L13. A primeira mobilizou conhecimentos pedagógicos gerais, que diziam respeito a estratégias de ensino-aprendizagem utilizadas por professores sem relação com conteúdos específicos.

Ele [o professor] estava com o projetor de slides para fazer uma dinâmica de questões de vestibulares e ENEM com a turma. O que me chamou atenção na tal dinâmica foi que em meio às questões de provas específicas surgiam questões "sem sentido", como por exemplo algo sobre o capítulo de uma novela da Globo [...]. Achei um método interessante porque é uma forma de descontrair os alunos em uma atividade que pode ser encarada como algo chato e cansativo, por toda a pressão e características que o ano de vestibular e os mesmos possuem (L11 - ND do componente curricular prática de ensino (abril) - individual).

Nessa ND, a licencianda destacou a vantagem da estratégia utilizada pelo professor para a preparação da turma que se encontrava em um contexto específico (momento de preparação para o ENEM). As ND referentes a abril e maio refletiram uma aproximação inicial com o contexto escolar e seu cotidiano, e foram baseadas em eventos que os licenciandos consideraram significativos para o seu percurso de aprendizagem.

Entre as narrativas articuladoras finais, L13 descreveu o desenvolvimento e a implementação de uma atividade de investigação criminal, trazendo também reflexões sobre o processo. A atividade foi desenvolvida com a ajuda de outros estagiários que não estavam realizando a disciplina, mas a narrativa foi produzida individualmente.

No final do mês passado, eu e as outras estagiárias do colégio tivemos nossa primeira coparticipação no Projeto IC Jr. Após observarmos algumas práticas fáceis 
e interessantes de serem feitas no site de educação da Fiocruz, optamos pelo tema investigação criminal. [...] Com isso, colocamos na nossa "cena do crime" elementos que muitas já viram em filmes ou séries de TV - como o formato do corpo desenhado no chão ou os termos científicos - para que pudéssemos pegar essas ideias e conceitos já estabelecidos em algum momento e construir algo mais investigativo e crítico em relação à ciência. Assim, foram feitas as atividades de coleta de pegadas e fios de cabelo, digitais, identificação do possível sangue na cena do crime e extração de DNA — através da prática de extração do DNA do morango - e identificação das bases nitrogenadas do material coletado de cada suspeita a fim de comparar com o obtido na cena do crime. Com as informações compartilhadas no final, os alunos escreveram suas observações e os indícios obtidos para que ao final pudessem criar uma hipótese do que poderia ter acontecido, argumentando o porquê de ter tomado tal decisão. Ao final podíamos ver a animação dos alunos em coletar as evidências e produzir hipóteses sobre o que tinha acontecido (L13 - narrativas articuladoras finais - narrativa individual).

É importante ressaltar que as narrativas articuladoras finais tinham como base uma reflexão que reunia os conhecimentos pedagógicos (trabalhados prioritariamente no componente curricular prática de ensino) e os conhecimentos de conteúdo (mobilizados a partir das atividades realizadas nos primeiros momentos da disciplina eletiva). Assim, a análise dessas ND indica uma construção de conhecimentos a partir do confronto entre os conhecimentos mobilizados previamente, o que ocorreu com base no planejamento educacional acompanhado da implementação e da reflexão sobre todo o processo. Os licenciandos iniciaram tais ND descrevendo a atividade desenvolvida e implementada na escola.

Tendo em vista que, nessa atividade, os licenciandos partiram de um conceito científico a ser trabalhado (situado na demanda escolar, como, por exemplo, reações químicas) e precisavam pensar em uma problemática mais ampla para servir como base (como acidificação dos oceanos), eles apresentaram uma dificuldade inicial para fazer essa relação. Houve então diversas discussões em sala de aula, envolvendo os licenciandos, as pesquisadoras e a professora Catarina para o planejamento das atividades, oportunizando uma reflexão integrada entre conteúdo e estratégias pedagógicas. A maior parte apresentou propostas iniciais diferentes da intenção da disciplina, de planejar algo investigativo. A diferença entre atividades investigativas e expositivas foi estabelecida, nesta pesquisa, com base na ideia da centralidade do problema (perguntas), como definido por Carvalho e Gil-Pérez (2011). No início do planejamento, os licenciandos apresentaram atividades mais expositivas e posteriormente adaptaram-nas a partir das conversas, bem como dos estímulos das pesquisadoras e da professora.

Segundo Newsome (2002), mesmo quando os professores se deparam com abordagens que privilegiam uma visão mais ampliada sobre conteúdo escolar, eles têm dificuldade de visualizar sua implementação na prática. Por isso, tendem a utilizar estratégias mais simples e mais similares àquelas com as quais já estão acostumados. Embora esses sujeitos estivessem em formação inicial, eles podem ter construído suas estruturas a partir das vivências experimentadas como alunos, durante sua vida 
escolar e universitária. Dessa maneira, acreditamos que esse momento constituiu para eles uma oportunidade de aprendizagem, tendo em vista que precisaram exercitar a intelectualidade e a autonomia, ao ser provocados a pensar estratégias pedagógicas que buscassem uma visão contextualizada dos conteúdos indicados pelos professores regentes. Além disso, este movimento pode ter auxiliado os sujeitos a desenvolver o que Mizukami (2004) chama de "repertório representacional" para as matérias que estão ensinando. Segundo a autora, "quando um repertório representacional amplia-se, ele pode enriquecer ou expandir a compreensão que o professor tem da matéria” (p. 7).

A segunda tendência, por sua vez, aponta que, de maneira geral, as ND que apresentaram maiores níveis de reflexão mobilizaram principalmente conhecimentos pedagógicos de conteúdo, enquanto as de menor reflexão apresentaram mais conhecimentos pedagógicos, como pode ser visualizado na Figura 2.

\begin{tabular}{|l|l|}
\hline Tipos de conhecimento & Níveis de reflexão \\
\hline \multirow{4}{*}{ Conhecimentos pedagógicos } & Escrita descritiva $(\mathrm{n}=3)$ \\
& Reflexão descritiva $(\mathrm{n}=6)$ \\
& Reflexão crítica $(\mathrm{n}=2)$ \\
& Reflexão dialógica $(\mathrm{n}=1)$ \\
\hline \multirow{3}{*}{ Conhecimentos pedagógicos de conteúdo } & Reflexão descritiva $(\mathrm{n}=1)$ \\
& Reflexão crítica $(\mathrm{n}=3)$ \\
& Reflexão dialógica $(\mathrm{n}=4)$ \\
\hline
\end{tabular}

Figura 2. Relação entre tipos de conhecimentos mobilizados e níveis de reflexão segundo a abordagem de Moon (2011) entre as narrativas digitais analisadas $(n=20)$

Para exemplificar essa tendência, são apresentadas as ND produzidas por L6 e L9. L6 discorreu sobre a importância das aulas práticas como forma de aproximação entre os atores do contexto escolar, alunos, professores elicenciandos, ressaltando principalmente que este processo permite mais participação do licenciando, mobilizando conhecimento pedagógico geral.

As aulas práticas têm um efeito muito positivo nas relações escolares não só pela fixação dos conteúdos teóricos, mas também no estreitamento das relações estagiários/alunos. No momento da prática se rompe a barreira invisível que torna o estagiário de um observador pouco atuante em um componente importante do processo de educação escolar que além de atuar em conjunto com os professores, na elaboração do plano de aula, também ministra as atividades e participa diretamente das correções das avaliações dos alunos. [...] Sendo assim, gostaria de destacar nesse relato a importância da aula prática não só para a formação escolar dos alunos e acadêmica dos estagiários, mas também para as relações que são estabelecidas entre os diferentes atores nesse tipo de atividade (L6 - ND do componente curricular prática de ensino (maio) - individual).

A licencianda desenvolveu essa narrativa a partir de uma aula que ministrou junto com alguns pares na escola e, embora não tenha descrito a aula, ainda assim pontuou as questões para reflexão, ao dizer que as aulas práticas têm potencial para 
o estabelecimento de relações entre os atores do processo educativo. Tal constatação caracterizou uma volta para o evento, havendo um diálogo interno, o que definiu uma reflexão descritiva.

L9, por sua vez, demonstrou compreender como o aprendizado é ancorado nos saberes e vivências dos indivíduos e como isso precisa ser levado em consideração no processo educativo.

Após um mês de observação da turma 2005, concluindo o conteúdo, trago alguns pontos que me fizeram refletir sobre a necessidade de explorar mais a pedagogia enquanto leque amplo, capaz de incluir e excluir concomitantemente diferentes pessoas - em outras palavras, produzir abjeções. A turma 2005, e todas com o final 5 no número, fazem parte de um projeto pedagógico da escola, que tenta satisfazer as necessidades do grupo, sendo este carente de algumas questões: tempo para o estudo, família, concentração. Acompanhando as demais turmas do segundo ano, percebi que a 2005 caminhava a passos mais lentos e com dificuldades mais marcantes nos conceitos prévios exigidos pela matéria. Por outro lado, era a turma mais presente no que diz respeito à participação e a atenção. [...], possuem uma história diferente dos demais alunos: muitos são mães/ pais. As perguntas que faziam, ao meu ver, traziam uma bagagem pessoal muito forte: contracepção, desenvolvimento, sentidos (contato mãe/bebê). [...] Esse tipo de pergunta me faz perceber a renovação de cada aula como uma fênix e me fez enxergar diversas brechas nas aulas para se explorar construções sociais (como o laço familiar) [...] (L9 ND do componente curricular prática de ensino (abril) - individual).

A licencianda mobilizou conhecimentos sobre os conhecimentos dos alunos, tendo em vista que levantou reflexões sobre o comportamento e a receptividade dos alunos com relação a atividades realizadas pelos professores abordando conteúdos específicos. Ela demonstrou compreender como o aprendizado é ancorado nos saberes e vivências dos indivíduos e como isso precisa ser considerado no processo educativo. No caso específico, teceu considerações sobre como o conteúdo de replicação celular ganhou contornos particulares ao ser trabalhado em uma turma de mães/pais. Isso foi feito a partir de um nível de reflexão dialógica, analisando mudanças em suas próprias visões sobre o ocorrido e reconhecendo o contexto social em que o evento aconteceu.

Com base nesses aspectos, o pensamento reflexivo se destacou como modo de mobilização e integração de conhecimentos, ajudando a formar o PCK. Ao propor esse constructo, Shulman (2014) ressaltou o papel da reflexividade docente para a sua formação. Segundo o autor, uma prática educativa reflexiva e raciocinada possibilita a construção de novos conhecimentos, tanto sobre assuntos que devem ser abordados no ensino quanto sobre alunos e aspectos pedagógicos em si.

Por fim, a terceira tendência aponta que as ND que apresentaram maior nível de reflexão sobre os eventos motivadores (como aulas e atividades didáticas implementadas), o fizeram devido a maior oportunidade de problematizar esses eventos, normalmente por meio de discussões (entre si, com as professoras e as pesquisadoras). A narrativa de abril de L5, por exemplo, ao mobilizar conhecimentos sobre os contextos educacionais, relatou o evento em que uma aluna foi proibida de entrar no colégio por estar calçando 
chinelo em vez de tênis.

Uma conversa entre a diretora e uma aluna me chamou a atenção. A aluna estava usando chinelos e alegou que o dedo do pé estava machucado e que, portanto, não poderia usar sapato fechado, como exige a regra da escola. A diretora demonstrou sua insatisfação, dizendo que ela deveria usar apenas chinelo no pé machucado. De início, estranhei a situação. Pensei que o rigor tinha sido excessivo apenas por usar o chinelo. Porém, depois de reflexão e discussão com a nossa turma de didática, consegui olhar com outros olhos. A utilização de um uniforme específico para os alunos, apesar de retirar suas liberdades de escolha em relação às vestimentas, também acaba sendo uma forma de controle dos alunos, visto que um chinelo pode provocar alguns acidentes (ND do componente curricular prática de ensino (abril) - individual).

Nessa narrativa, L5 apresentou um nível de reflexão crítica, tendo em vista que analisou as mudanças em sua própria visão sobre o evento. Essa mudança foi possibilitada pelas discussões ocorridas durante uma disciplina teórica. Esse confrontamento com outras opiniões estimulou uma reflexão mais profunda por parte da licencianda, fazendo-a questionar suas concepções prévias e mudar sua opinião, o que ressalta como a problematização e a discussão possibilitam reflexão mais ampla. Com isso, foi corroborada a importância da teorização para que a experiência e a prática de trabalho sirvam como base para a construção de conhecimentos. Roldão (2017) defende o embasamento do trabalho por domínios teóricos a fim de evitar constatações desvirtuadas de análise, que podem gerar generalização sem justificação.

Entre as narrativas articuladoras finais, L5, L6 e L7 descreveram uma atividade em que, tendo recebido a demanda do professor regente de ministrar uma aula prática sobre reações químicas para alunos do sexto ano do ensino fundamental, optaram por partir da problemática de acidificação dos oceanos.

Como estagiários da escola uma das nossas funções é planejar e executar aulas práticas de temas já predefinidos pelo professor regente. E como parte da disciplina tópicos em ensino de ecologia deveríamos implementar uma atividade investigativa que fosse adaptável às necessidades e exigências da escola. A única aula disponível para a realização de tal atividade foi uma aula prática sobre reações químicas [...], a partir de uma série de discussões entre o grupo, a [Catarina] e a [pesquisadora], decidimos abordar o tema reações químicas por um viés biológico, pois dessa forma os alunos poderiam estabelecer mais conexões entre os conteúdos e suas implicações no setor social, econômico e ambiental. Para isso estabeleceu-se um dos assuntos que seriam tratados na prática que seria "efeitos da acidificação dos oceanos". Após o assunto ser determinado, fomos atrás de um experimento que ajudaria os alunos a estabelecer conexões entre o tema central e o assunto escolhido e que fosse de fácil execução e materiais acessíveis, ao mesmo tempo que encaramos a difícil tarefa de garantir uma atividade investigativa e não apenas demonstrativa. A fim de garantir tal característica, nós abrimos mão de uma postura explicativa. Com isso, ao longo de toda aula os alunos deveriam propor hipóteses e responder a questões que possibilitariam a reflexão e análise de uma série de fatores. [...] Outro ponto que nos deu muita dificuldade foi na 
hora de relacionar os materiais da prática e o desenvolvimento do experimento com o embasamento teórico na biologia e na química, pois após a fase final da prática, em que os alunos deveriam assimilar os conteúdos, muitos acabaram se perdendo ou perderam o interesse na teorização da prática. Consideramos, portanto, que essa problematização poderia nos fazer repensar certas partes da prática, na tentativa de preparar um material menos extenso e que tornasse o conteúdo mais interessante para os alunos (L5, L6 e L7 - narrativas articuladoras finais - narrativa em grupo).

A narrativa começou com uma descrição da atividade realizada, relacionada com a mobilização de conhecimentos sobre estratégias de ensino-aprendizagem e sua utilização para diferentes contextos e objetivos, um conhecimento pedagógico de conteúdo. Os licenciandos fizeram uma descrição detalhada da aula prática, incluindo aspectos como: forma de abordagem do tema, problemática escolhida e conceitos científicos trabalhados, divisão dos alunos em grupos, materiais utilizados, entre outros.

Nessa narrativa, é possível ressaltar alguns pontos principais: o primeiro diz respeito ao fato de os licenciandos comentarem a dificuldade de adaptar o experimento, encontrado na internet, a fim de realizar uma prática que não fosse expositiva. Nesse momento, ressaltaram o papel da intervenção da professora e de uma das pesquisadoras como incentivadoras para que o foco da aula fosse investigativo. Também em discussões durante a aula, apontaram o trabalho dispensado na atividade de planejamento, afirmando que precisaram construir as questões que seriam propostas para os alunos e ressaltando a dificuldade envolvida nesse processo. Percebeu-se, portanto, como essas discussões e o planejamento cuidadoso os estimularam a aprofundar as reflexões.

Outro ponto se refere à inclusão pelos licenciandos, ao narrar uma questão que os intrigou com relação aos alunos durante a realização das atividades, de uma proposta de adaptação, que poderia ser adotada em implementação posterior. Afirmaram que os alunos participantes da atividade apresentaram dificuldade em assimilar os conhecimentos teóricos estudados, apontando que tal fato poderia estar relacionado à quantidade de material disponibilizada. Ou seja, realizaram uma reflexão, a partir da implementação, que constituiu um precursor para os conhecimentos sobre os alunos, e esse, por sua vez, estimulou a repensar estratégias de ensino-aprendizagem. Destacase, então, um movimento em trânsito entre os diferentes conhecimentos, em que uns servem de base para outros, por meio da reflexão. Esse movimento foi feito a partir de autoquestionamento, tendo em vista que os licenciandos demonstraram questionar a forma como conduziram a atividade. Eles se aproximaram, assim, da reflexão dialógica, considerando os níveis de reflexão propostos por Moon (2001).

As narrativas articuladoras finais foram realizadas após discussões em sala de aula tanto sobre o planejamento quanto sobre a implementação. Além disso, foi pedido aos sujeitos que incluíssem reflexões sobre todo o processo. De acordo com Russo (2016), dessa forma é possível desenvolver um planejamento menos burocratizado e mais dinâmico, oportunizando aos futuros professores analisar as práticas até então adotadas.

Essa tendência é reforçada se analisarmos, como contraponto, a narrativa de L10 
referente ao mês de maio. Em tal ND, produzida como parte do estranhamento inicial da escola, o licenciando mobilizou conhecimentos (ou precursores de conhecimentos) sobre os alunos, um conhecimento pedagógico, posto que refletia sobre comportamentos e dificuldades desses sujeitos.

A turma 1005 é uma turma de projeto pedagógico - composta por alunos que têm tido mau desempenho escolar nos anos anteriores. [...] na minha mente, já que esses alunos estão numa turma separada, pensada para lidar melhor com suas dificuldades de aprendizado, as aulas serão diferentes daquelas das outras turmas. [...] Penso que, estando separados, qual é o sentido de dar a mesma aula, conteúdo igual, as mesmas questões, os mesmos exemplos? Se for assim, qual sentido de separar? Eu não sei mesmo, pode ser ignorância, mas eu não sei. Mas vamos fazer um teste... A prova está chegando, vamos ver como eles vão se sair, comparando com as outras turmas. [...] Resultado: quase $85 \%$ da turma em recuperação. [...]. Eu não sei bem se dividir os alunos dessa forma pode dar certo, pode até ser que sim. Mas penso que não vai dar certo enquanto todo o restante for igual (L10 - ND do componente curricular prática de ensino (maio) - individual).

O licenciando mobilizou esses conhecimentos a partir de um nível de reflexão descritiva, pois apontou uma questão para reflexão e deixou em aberto, como forma de destacar a necessidade de problematizar e pensar em uma possível resposta. A partir disso, é possível inferir que essa narrativa abre precedente para um aprofundamento, possivelmente servindo para que os conhecimentos pedagógicos mobilizados fossem mais bem consolidados, ou mesmo mobilizando conhecimentos pedagógicos de conteúdo. Ressalta-se que as ND do componente curricular prática de ensino normalmente trouxeram diferentes reflexões que, de maneira geral, não foram aprofundadas e problematizadas. Como resultado, muitas delas traziam uma visão sobre a prática dos professores desconectada da teoria e também de questionamentos sobre o conteúdo. Segundo Roldão (2017), na formação inicial é comum uma reflexão simplificada devido à existência de ideias do senso comum. Entretanto, essas ND foram o resultado do início do processo de inserção dos licenciandos na escola, da observação e do exercício de "estranhamento do familiar". Constituíram, então, um passo importante em sua formação, tendo em vista que, como apontado por Roldão (2017), é necessário conhecer o contexto no qual se procura implementar práticas pedagógicas apoiadas em teorizações.

De acordo com essas tendências, é possível identificar vantagens no desenvolvimento dessas ND para a formação dos licenciandos, no que tange ao movimento de reflexão sobre a prática (práxis) como forma de construção e integração de conhecimentos (formando o PCK). Como apresentado, narrativas com níveis mais elevados de reflexão, de maneira geral, desenvolviam melhor o PCK. Acredita-se que a produção de relatos pouco burocráticos e com foco no cotidiano tenha favorecido essa dinâmica. Além disso, tais ND foram bastante autorais, o que possibilita, de acordo com Backes (2012), a construção de novos conhecimentos com base em conhecimentos prévios. Tal fato pode ser observado nas narrativas digitais analisadas devido ao 
movimento em trânsito entre diferentes tipos de conhecimento.

Para contribuir com essas discussões, um aspecto importante a ser mencionado é a utilização do Facebook, uma rede social que fazia parte do cotidiano da maioria dos licenciandos (fato apontado por eles próprios). O uso desse tipo de plataforma está associado às mudanças nas formas de produção de textos e ao surgimento de novas manifestações da língua. Merli (2016) afirma que, considerando que a linguagem é viva, suas manifestações se modificam conforme o contexto sociocultural. Assim, a produção de ND nesse espaço virtual pode ter facilitado a aproximação com a ideia da "contação de histórias", que foi proposta pelas pesquisadoras e adotada pelos licenciandos, possibilitando a construção de novos conhecimentos a partir da produção de narrativas digitais.

Mudanças entre as formas de comunicação na era do papel e da tela também são apontadas por Kress (2003), de acordo com quem, embora os indivíduos normalmente adequem as diferentes tecnologias às suas necessidades e demandas, também a forma desses recursos propicia uma determinada expressão dos significados que os indivíduos constroem. $\mathrm{O}$ autor assim destaca as diferenças entre o discurso formal e o informal, que carregam diferentes relações de poder. Pode-se inferir, então, que o espaço virtual do Facebook é menos marcado pela lógica de poder normalmente contida em relatórios feitos em processadores de textos para posterior entrega.

Finalmente, vale mencionar que, tendo em vista a importância de apresentar as ND em sua íntegra, de maneira a não descaracterizar o processo reflexivo, os excertos utilizados nessa fase expõem aspectos para além daqueles em que o trabalho se deteve em analisar consoante com os objetivos de pesquisa. As ND, por exemplo, apresentaram reflexões dos licenciandos de diferentes naturezas (argumentações, problematizações, questionamentos) sobre eventos variados (como aulas e atividades educativas realizadas pelos professores regentes ou pelos próprios licenciandos); e mais, reflexões que, segundo nosso referencial de análise, permitiram apontar diferentes subtipos de conhecimento (como conhecimentos sobre estratégias de ensino-aprendizagem e sua utilização para diferentes objetivos). Estudos futuros poderão dedicar-se à análise desses aspectos.

\section{Reflexão e documentação para a construção de princípios de design}

Nessa fase, foram realizados o resgate, a sistematização e a análise do processo de pesquisa e desenvolvimento, a fim de produzir princípios de design. Tais princípios, pautados no referencial teórico e na prática vivenciada, buscam contribuir com o desenho deprocessos deformação deprofessoresquetêm comoobjetivodesestabilizaras dicotomias entre teoria e prática e entre conhecimentos pedagógicos e de conteúdo. As contribuições das professoras e das pesquisadoras tiveram papel fundamental para o percurso do Itinerário formativo articulador e para apoiar os licenciandos na desestabilização das dicotomias. A professora Clarice teve papel central na problematização das concepções dos sujeitos sobre a profissão docente e sobre o processo ensino-aprendizagem. Isso foi 
possibilitado pela familiaridade com as últimas etapas da licenciatura e pelas concepções, amplamente problematizadas, sobre a formação de professores de ciências biológicas. Catarina, por sua vez, buscava soluções para questões colocadas por Clarice e pelas pesquisadoras, mobilizando amplamente seus conhecimentos sobre o conteúdo. Sua participação foi fundamental para o desenvolvimento de uma disciplina que, embora voltada principalmente para problematizar o conteúdo, procurava apoiar os licenciandos na construção dos conhecimentos pedagógicos de conteúdo, uma vez que extrapolava para as questões pedagógicas. Além disso, as pesquisadoras participaram ativamente do processo, contribuindo com todas as etapas e mediando o diálogo.

Ao final, também ocorreu uma avaliação conjunta sobre o artefato pedagógico, em que foram discutidos os vários aspectos e as estratégias formativas que melhor responderam aos objetivos pretendidos, assim como aqueles que poderiam ser repensados. Como síntese da análise do processo de pesquisa e desenvolvimento do Itinerário formativo articulador, foram definidos os seguintes princípios de design: a) a práxis pedagógica pode servir como base para a formação do PCK, posto que apoia a construção e a integração de conhecimentos; b) o ato de narrar as experiências vivenciadas pelos licenciandos nas escolas é um importante ponto de partida para as reflexões teóricas, apoiando o processo de desestabilização das dicotomias; c) a produção de narrativas digitais pelos licenciandos configura-se como uma atividade oportuna para a desestabilização das dicotomias, podendo o formato de integração dos recursos tecnológicos no Itinerário formativo articulador ser repensado, a fim de potencializar ainda mais esse percurso; e d) as redes sociais, porque intensificam as possibilidades de comunicação e compartilhamento de experiências, podem ser exploradas a fim de possibilitar articulação mais ampla entre as ND e os contextos presenciais do Itinerário formativo articulador, estimulando a reflexão sobre os eventos observados.

Esses princípios foram formulados a partir da ideia de que determinadas estratégias formativas podem estimular a problematização e a reflexão, a fim de potencializar a construção e a integração de conhecimentos (formação do PCK), tendo como base as próprias ND. Assim, é possível inferir que o movimento de reflexão incentivado pela construção das ND pode ter facilitado a formação do PCK. Isso porque, ao analisar o que era vivenciado nas escolas, os licenciandos atingiam um nível mais elevado de consciência sobre suas percepções dos eventos observados, construindo, a partir disso, novos conhecimentos. A consciência, segundo alguns autores em que nos baseamos neste trabalho (Freire, 1987; Pio, Carvalho \& Mendes, 2014), é capaz de transformar a prática pedagógica em práxis, uma vez que pode potencializar essa prática como guia de transformação. A transformação é possibilitada pelo surgimento do conceito de sujeito, tendo em vista que o homem passa a ser produto e criação de sua própria atividade (Pio et al., 2014).

Dessa forma, a práxis pedagógica surgia como forma de estimular os licenciandos a integrar diferentes conhecimentos, pois os possibilitava mobilizar conhecimentos prévios, confrontá-los com os eventos observados, permitindo-lhes problematizá-los, 
reformulá-los e construir novos conhecimentos ao longo desse percurso. Então, as ND desenvolvidas no processo do Itinerário formativo articulador auxiliaram a construção de conhecimentos de maneira cíclica e não linear, e diversos conhecimentos serviram de base uns para os outros durante esse tempo. Esse processo refletiu a natureza complexa de formação de conhecimentos, que Shulman (2014) caracteriza como amálgama de conteúdo e pedagogia próprio do trabalho docente, justamente pela dinamicidade de sua constituição. De acordo com esse autor, a formação do PCK é um processo que começa com o raciocínio, culmina em ações pedagógicas e retorna à reflexão, dando início a um novo ciclo de aprendizagem.

Esse caminho foi facilitado pela implementação das atividades planejadas, o que mostra a natureza dinâmica do processo de planejamento. Como apontado por Russo (2016), nem sempre é possível prever as condições reais em que uma ação ocorrerá, o que exige ajustes e reflexões sucessivos de acordo com sua ocorrência. Sob essa perspectiva, o principal produto desse planejamento não é material, mas consiste na melhoria da prática pedagógica dos professores e no seu desenvolvimento profissional (Russo, 2016).

Apesar da importância da formação de diversos tipos de conhecimentos pedagógicos, é possível apontar que os questionamentos dos conteúdos abordados nas escolas pode ter estimulado os licenciandos a refletir mais profundamente, e, de forma semelhante, a reflexão pode ter apoiado o processo de questionamento dos conteúdos. Isso é importante tendo em vista que, conforme apontado por Clarice na fase de análise do problema pedagógico, os professores em formação inicial tendem a ver o conteúdo de maneira naturalizada.

Adotar a produção de narrativas digitais como estratégia para apoiar esse processo pode ser interessante, tendo em vista que elas constituíram escolhas dos próprios licenciandos, refletindo eventos e situações que chamaram a atenção desses sujeitos. Segundo Almeida e Valente (2012), quando se lida com ND voltadas para o ensino, se os conteúdos nelas presentes forem analisados, os conhecimentos demonstrados podem ser trabalhados e depurados, o que cria condições para que os estudantes realizem uma "espiral de aprendizagem" e, assim, construam novos conhecimentos.

Com isso, não estamos defendendo que a formação inicial não deva incluir conhecimentos teóricos sem correlação direta com a prática que os licenciandos estão vivenciando no momento. Pelo contrário, o campo educacional e a educação em ciências apresentam diversas reflexões que auxiliam na formação do sujeito e, em consequência, do professor. Considerando, entretanto, o tempo limitado da formação inicial, o emprego de atividades em que haja um estímulo ao confronto entre as vivências dos licenciandos e as discussões trazidas por autores da área, por exemplo, pode servir como um exercício em que eles se preparem para estabelecer, de maneira autônoma, relações entre a teoria e a prática. Trabalhar essa autonomia é importante, tendo em vista que as bases de conhecimentos relacionadas com a profissão docente não são fixas e definitivas (Shulman, 2014), e os professores em formação devem estar preparados para a construção contínua de conhecimentos. 
Para isso, uma maior articulação entre as ND e o percurso do Itinerário formativo articulador poderia possibilitar reflexão mais ampla por parte dos licenciandos. O próprio formato digital facilita essa articulação, pois, segundo Rodrigues (2017), ambientes virtuais possuem como uma de suas características a universalidade, o que permite que uma quantidade maior de pessoas possa produzir narrativas por meios digitais como resultado da difusão rápida e generalizada das tecnologias. As possibilidades de compartilhamento e reelaboração das ND auxiliam na escrita de relatos mais fluidos, tendo em vista que as narrativas não precisam ser entregues e podem ser resgatadas e rememoradas a qualquer momento.

No presente trabalho, as mídias digitais não foram utilizadas de maneira a promover a interatividade e a comunicação entre os sujeitos. Embora seja possível observar a formação de uma rede de trabalho colaborativo voltada, por exemplo, para o planejamento educacional, as discussões foram realizadas presencialmente. Futuras iniciativas de formação de professores mediadas por TDIC podem, entretanto, buscar utilizar o potencial dos recursos tecnológicos para fortalecer redes de aprendizagem.

\section{Conclusão}

Este trabalho narrou o processo de pesquisa e desenvolvimento do Itinerário formativo articulador, um percurso de ensino-aprendizagem voltado para a formação de professores de ciências biológicas. Partiu de uma problemática relevante para a formação, as dicotomias entre teoria e prática e entre conhecimentos pedagógicos e de conteúdo, e, por meio de uma abordagem de pesquisa colaborativa e situada na prática, definiu princípios de design para contribuir com a construção de conhecimentos e a formulação de iniciativas semelhantes.

Considerando esse objetivo, o referencial teórico-metodológico adotado, a narrativa do trabalho e os resultados buscaram não apenas reforçar a contribuição da pesquisa baseada em design (PBD) como abordagem para o desenvolvimento e análise de artefatos pedagógicos, mas sua disseminação no campo de pesquisa em educação em ciências. De acordo com Juuti e Lavonen (2006), tal disseminação é importante, tendo em vista que o processo de ensino-aprendizagem das ciências é um fenômeno permeado por diversas variáveis, como o contexto de sala de aula, o estado psicológico, a motivação dos alunos, as concepções sobre a importância dos tópicos abordados, bem como experiências vivenciadas fora do ambiente escolar (como contato com notícias e opiniões veiculadas pela mídia). A escolha da PBD como referencial teóricometodológico poderia, então, favorecer o desenvolvimento de pesquisas que considerem tais variáveis (Juuti \& Lavonen, 2006).

No presente estudo, a sistematização dos achados incluiu a forma como o problema pedagógico foi discutido teoricamente por meio dos constructos da práxis pedagógica, da reflexão e do PCK, passando pela caracterização dos pressupostos que nortearam a definição das estratégias formativas (diretamente articuladas aos problemas pedagógicos) e, finalmente, os achados relativos ao modo como esse artefato pedagógico 
permitiu desestabilizar as dicotomias entre teoria e prática e entre conhecimentos pedagógicos e de conteúdo. Tal percurso evidencia a busca de uma abordagem de pesquisa e desenvolvimento situada na prática e na teoria. Assim, ao mesmo tempo em que o trabalho apresentou um modelo formativo que pode ser refinado, aplicado e estudado em novos ciclos de intervenção, no contexto da licenciatura em ciências biológicas, o fez de maneira a revelar os princípios teórico-práticos norteadores e as tendências encontradas no que diz respeito ao potencial do Itinerário formativo articulador desenvolvido.

A análise das narrativas digitais (ND) produzidas pelos licenciandos indicou que o Itinerário formativo articulador contribuiu para a problematização e desestabilização das dicotomias, uma vez que o percurso reflexivo promovido pelas estratégias adotadas (como planejamento teoricamente embasado, implementação de atividades educativas) apoiou a construção, a mobilização e a integração dos conhecimentos. Em especial, vale pontuar que a reflexão sobre o processo de planejamento e implementação de atividades orientadas pela investigação de temáticas CTSA favoreceu a construção de uma visão ampliada e contextualizada de conteúdo, relacionada ao desenvolvimento do PCK. Essas estratégias podem ser analisadas por pesquisadores da área de educação em ciencias e adotadas (singularmente ou combinadas) em iniciatiavas de formação de professores de ciencias biológicas, contribuindo para minimizar a problemática das dicotomías entre teoría entre teoría e prática e entre conhecimentos pedagógicos e de conteúdo que, segundo Madeira (2012), são recorrentes na formação docente.

Ofatodeasnarrativas articuladoras finaisterem sidoaquelas em queo PCKemergiu mais fortemente revela uma importante contribuição que merece aprofundamento: a articulação entre disciplinas, com atividades integradas e concomitantes, pode potencializar a construção de uma visão que considere os diferentes saberes e práticas dos campos de referência pedagógicos e das ciências naturais para a profissão docente. Nesse percurso, a produção de ND configurou importante elemento integrador e pode ser utilizada em implementações futuras a fim de posibilitar aos licenciandos confrontar suas primeiras impressões ao vivenciar os eventos (registradas nas narrativas) e aquelas construídas a partir de problematizaçoes posteriores. Tal confronto contribui para a construção e integração contínua de conhecimentos, facilitando a formação do PCK (Shulman, 2014).

Finalmente, vale destacar que a articulação dos constructos da práxis pedagógica e PCK conferiu uma importante lente para analisar os dados produzidos nessa intervenção, cujos princípios de design devem ser refinados e aplicados em trabalhos futuros.

\section{Agradecimentos}

Coordenação de Aperfeiçoamento de Pessoal de Nível Superior (CAPES)

Fundação de Amparo à Pesquisa do Estado de Rio de Janeiro (FAPERJ) 


\section{Referências}

Almeida, M. E. B., \& Valente, J. A. (2012). Integração currículo e tecnologias e a produção de narrativas digitais. Currículo sem Fronteiras, 12(3), 57-82.

Amiel, T., \& Reeves, T. C. (2008). Design Based Research and educational technology: Rethinking technology and the research agenda. Educational Technology \& Society, $11(4), 29-40$.

Backes, L. (2012). As manifestações da autoria na formação do educador em espaços digitais virtuais. Revista de Educação, Ciência e Cultura, 17(2), 71-85. http://dx.doi. org/10.18316/608

Ball, D. L., Roover, B. M., \& Phelps, T. G. (2008). Content knowledge for teaching: What makes it special? Journal of Teacher Education, 59(5). 389-407. https://oi. org/10.1177/0022487108324554

Bardin, L. (2004). Análise de conteúdo. Edições 70.

Batista, R. F., \& Silva, C. C. (2018). A abordagem histórico-investigativa no ensino de ciências. Estudos avançados, 32(94), 97-110. http://dx.doi.org/10.1590/s010340142018.3294.0008

Bazzo, W. A., Linsingen, I. V., \& Pereira, L. T. (2003). Introdução aos estudos CTS (Ciência, tecnologia e sociedade). https://www.oei.es/historico/salactsi/introducaoestudoscts.php

Cardoso, A. A., Del Pino, M. A. B., \& Dorneles, C. L. (2012). Os saberes profissionais dos professores na perspectiva de Tardif e Gauthier: Contribuições para o campo de pesquisa sobre os saberes docentes no Brasil. In Anais do $9^{\circ}$ Seminário de Pesquisa em Educação da Região Sul (ANPED-SUL) (p. 1), Caxias do Sul, RS.

Carvalho, A. M. P., \& Gil-Perez, D. (2011). Formação de professores de ciências: Tendências e inovações. 10. ed. Cortez.

DBRC - Design-Based Research Collective. (2003). Design-based research: an emerging paradigm for educational inquiry. Educational Researcher, 32(1), 5-8. https://doi. org/10.3102/0013189X032001005

Freire, P. (1987). Pedagogia do oprimido. 17. ed. Paz e Terra.

Gabriel, C, T. (2016). Conhecimento escolar e emancipação: uma leitura pós-fundacional. Cadernos de Pesquisa, 46(159), 104-130. https://doi.org/10.1590/198053143551

Juuti, K., \& Lavonen, J. (2006). Design-based research in science education: one step towards methodology. Nordina, 4, 54-68. https://doi.org/10.5617/nordina.424

Kress, G. (2003). Literacy in the new media age. Routledge, Taylor \& Francis Group.

Larrosa, J. (2004). Notas sobre narrativa e identidade. In M. H. B. Abrahão (Org.), A aventura autobiográfica: Teoria e empiria (pp. 201-224). EDIPUCRS. 
Madeira, A. V. M. (2012). A difícil superação das dicotomias teoria/prática e formação específica/pedagógica: Opções curriculares em licenciaturas em ciências biológicas. In R. S. Macedo, A. Pimentel, \& L. R. Reis (Orgs.), Currículos e processos formativos: experiências, saberes e culturas (pp.77-92). Editora UFBA.

McKenney, S., \& Reeves, T. C. (2013). Systematic review of design based research progress: Is a little knowledge a dangerous thing? Educational researcher, 42 (2), 97-100. https://doi.org/10.3102/0013189X12463781

Merli, A. C. G. (2016). Hipertexto, ciberespaço e internet: A confluência entre leitura e tecnologia. (Tese de Doutorado). Centro de Educação, Comunicação e Artes, Universidade Estadual do Oeste do Paraná, Cascavel, PR.

Mizukami, M. G. N. (2004). Aprendizagem da docência: Algumas contribuições de L. S. Shulman. Revista Educação, 29(2), 33-49. http://dx.doi.org/10.5902/19846444

Moon, J. (2001). A handbook of reflective and experiential learning: Theory and practice. Routledge farmer.

Newsome, J. (2002). Pedagogical content knowledge: an introduction and orientation. In J. Newsome, \& N. Lederman (Orgs.), Examining pedagogical content knowledge (pp. 3-20), KluwerAcademicPublishers.

Nóvoa, A. (2007). O regresso dos professores. In Anais da Conferência para o Desenvolvimento profissional de professores para a qualidade e para a equidade da aprendizagem ao longo da vida (p. 1). Lisboa, Portugal.

Nunes, K. R., \& Ventorim. S. (2017). Narrativas de formação docente: experiências no estágio supervisionado em educação física. Revista Contrapontos, 17(3), 460-484. https://doi.org/10.14210/contrapontos.v17n3.p460-484

Oliveira, M. M. (2017). Possibilidades, limites e desafios do Framework Technological Pedagogical Content Knowledge (TPACK) na formação de professores para a integração das TDIC na educação científica e tecnológica. (Dissertação de Mestrado). Universidade Federal de Santa Catarina, Florianópolis, SC.

Pio, P. M., Carvalho, S. M. D., \& Mendes, J. E. (2014). Práxis e prática educativa em Paulo Freire: reflexões para a formação e a docência. In Anais do $17^{\circ}$ Encontro Nacional de Didática e Prática de Ensino (ENDIPE) (p. 1), Fortaleza, CE.

Reeves, T. C. (2000). Socially responsible educational technology research. Educational Technology, 40(6), 19-28.

Ribeiro, M. R. F., Carvalho, F. S. P., \& Santos, R. (2018). Ambiências híbridas-formativas na educação online: desafios e potencialidades em tempos de cibercultura. Revista Docência e Cibercultura, 2(1). https://doi.org/10.12957/redoc.2018.30589

Rodrigues, A. (2017). Narrativas digitais, autoria e currículo na formação de professores mediada pelas tecnologias: Uma narrativa-tese. (Tese de Doutorado). Pontifícia Universidade Católica de São Paulo, São Paulo, SP. 
Roldão, M. C. N. (2017). Formação de professores e desenvolvimento profissional. Revista Educação, PUC-Campinas, 22(2), 191-202. https://doi.org/10.24220/23180870v22n2a3638

Rosa, I. S. C. (2014). Abordagem CTSA no ensino de ecologia: uma contribuição para a formação de cidadãos críticos. (Dissertação de Mestrado). Núcleo de Pós-graduação em Ensino de Ciências Naturais e Matemática, Universidade Federal de Sergipe, São Cristóvão, SE.

Russo, M. H. (2016). Planejamento e burocracia na prática escolar: sentidos que assumem na escola pública. Revista Brasileira de Política e Administração da Educação, 32(1), 193-210. https://doi.org/10.21573/vol32n012016.62356

Santos, E. F., Vieira, M. F., \& Santos, S. C. (2018). Ser professor: A importância da prática pedagógica do estágio supervisionado no ensino de ciências. In Anais do $11^{\circ}$ Encontro Internacional de Formação de Professores (p. 1), Aracaju, SE.

Shulman, L. S. (2014). Conhecimento e ensino: fundamentos para a nova reforma. Cadernos CENPEC, 4(2), 196-229. http://dx.doi.org/10.18676/cadernoscenpec.v4i2.293

Shulman, L. S. (1987). Knowledge and teaching: foundations of the new reform. Harvard Educational Review, 57(1), 1-22. https://doi.org/10.17763/haer.57.1.j463w79r56455411

Silva, L. N. D. (2011). Formação de professores centrada na pesquisa: A relação teoria e prática. (Tese de Doutorado). Faculdade de Educação, Universidade Federal de Goiás, Goiânia, GO.

Tardif, M. (2002). Saberes docentes e formação profissional. Vozes.

Wang, F., \& Hannafin, M. J. (2005). Design-based research and technology-enhanced learning environments. ETR\&D, 53(4), 5-23. https://doi.org/10.1007/BF02504682

Zeichner, K. M. (2008). Uma análise crítica sobre a "reflexão" como conceito estruturante na formação docente. Educação \& Sociedade, 29(103), 535-554. https://doi.org/10.1590/ S0101-73302008000200012

\section{Rosilaine de Fátima Wardenski}

https://orcid.org/0000-0002-3026-2971

Universidade Federal do Rio de Janeiro Instituto NUTES de Educação em Ciências e Saúde

Rio de Janeiro, Rio de Janeiro, Brasil rosiwardenski@gmail.com 


\section{Margarete Valverde Macedo}

${ }^{\oplus}$ https://orcid.org/0000-0002-4170-9679 Universidade Federal do Rio de Janeiro Instituto de Biologia Departamento de Ecologia Rio de Janeiro, Rio de Janeiro, Brasil margaretevmacedo@gmail.com

\section{Maria Margarida Gomes}

${ }^{0}$ https://orcid.org/0000-0002-8609-3898 Universidade Federal do Rio de Janeiro Faculdade de Educação Departamento de Didática Rio de Janeiro, Rio de Janeiro, Brasil margaridaplgomes@gmail.com

Rafaela Ferreira dos Santos

https://orcid.org/0000-0003-1722-1822 Universidade Federal do Rio de Janeiro Instituto NUTES de Educação em Ciências e Saúde Rio de Janeiro, Rio de Janeiro, Brasil rafiferreira22@gmail.com

Tais Rabetti Giannella

${ }^{0}$ https://orcid.org/0000-0001-9563-2964 Universidade Federal do Rio de Janeiro Instituto NUTES de Educação em Ciências e Saúde Rio de Janeiro, Rio de Janeiro, Brasil taisrg@yahoo.com.br

Submetido em 19 de abril de 2020 Aceito em 15 de julho de 2020 Publicado em 08 de setembro de 2020 